\title{
L- Carnitine Decreases Her-2/neu in Breast Cancer Patients Treated with Tamoxifen
}

\author{
Rania M. Khalil ${ }^{1}$, Hoda A. El-Bahrawy ${ }^{1}$, Nahla E. El-Ashmawy ${ }^{1}$, Hossam \\ Darwish $^{2}$ \\ ${ }^{1}$ Biochemistry Department, Faculty of Pharmacy, Tanta University \\ ${ }^{2}$ Medical Oncology, Damietta Cancer Institute, Egypt
}

\begin{abstract}
Background: The crosstalk between the estrogen receptor $(E R)$ and the growth factor receptor pathways is implicated in breast cancer cell growth. L-carnitine as complementary medicine may help reducing therapy-associated toxicity or improving cancer-related symptoms. The possible role of L-carnitine to modulate IGF-1 and Her-2/neu in breast cancer patients maintained on tamoxifen, was investigated. Patients \& Methods: Two groups of postmenopausal breast cancer patients were studied: Control group received no treatment $(n=20)$ and Tamoxifen (TAM)-treated group $(n=40)$. Blood samples were withdrawn at the start of study and then TAM group were supplemented with L-carnitine $(L-C A R)$ for 6 months, after which blood samples were collected. Results: TAM group before L-CAR administration showed significant decrease in serum CEA, CA15.3, Her-2/neu and IGF-1 levels compared to breast cancer control group. After L-CAR administration, a significant decrease in Her-2/neu was obtained compared to that before L-CAR, whereas the lowering effects of TAM on tumor markers and IGF-1 were preserved. Estradiol showed no significant difference between groups. Conclusion: L-carnitine as add-on therapy to TAM produced a further decrease in Her-2/neu and thus, may offer a better cancer prognosis, which may be a prospective trial to overcome TAM resistance.
\end{abstract}

Keywords: Breast cancer, Her-2/neu, IGF-1, L-carnitine, Tamoxifen.

\section{Introduction}

Tamoxifen (TAM) is an endocrine therapy that is widely used in the treatment of both early stage and recurrent/metastatic breast cancer. However, the long-term efficacy is limited by relapse of disease and development of resistance following adjuvant endocrine therapy [1].

TAM, the prototype selective estrogen receptor modulator (SERM), exerts its effect by binding to the estrogen receptor (ER) and altering the conformation of the complex, thereby inhibiting signal transduction cascades that stimulate cell replication [2].

Unfortunately, up to 50\% of patients with ER-positive breast cancer who develop metastatic disease do not respond to first-line endocrine treatment (de novo resistance), and the remainder will eventually relapse despite an initial response (acquired resistance). Efforts to understand the various biologic mechanisms responsible for the development of endocrine resistance are directed to the development of new strategies to enhance the efficacy of therapy for ER-positive breast cancer [3].

Overexpression of Her-2/neu in ER-positive breast cancer cells can cause tamoxifen to behave as an agonist and stimulate cell growth. Implicit in this mechanism for resistance is cross-talk activation between the ER and the epidermal growth factor receptor (EGFR/Her-2/neu) pathways [3]. Treatment with various signal transduction inhibitors has been used in combination with endocrine therapy to overcome resistance, such as gefitinib, which targets the internal tyrosine kinase domain of EGFR, and trastuzumab, which blocks the external domain of Her-2/neu [4].

Recently, complementary and alternative medicine (CAM) is widely accepted among patients with breast cancer, which may provide several beneficial effects including reduction of therapy-associated toxicity, improvement of cancer-related symptoms, fostering of the immune system, and even direct anticancer effects [5].

Carnitine is a trimethylated amino acid, naturally synthesized in the liver, brain and kidney from proteinbound lysine and methionine. Several factors such as sex hormones and glucagon may impact on carnitine distribution and level in tissues [6]. L-carnitine plays an important role in cell energy metabolism through mediating the transport of long chain fatty acids across the inner mitochondrial membrane. Carnitine has a modulating effect on the function of acetylcholine excitatory neurotransmitter, glutamate excitatory amino acid, insulin growth factor-1 (IGF-1) and nitric oxide (NO). L-carnitine may have a dual protective effect by enhancing the energy dynamics of the cell and inhibiting cell membrane hyperexcitability, which make it an ideal nutrient for cancer prevention and treatment [7]. 
The present work tried to investigate the possible role of L-carnitine, as add-on therapy to breast cancer patients maintained on tamoxifen, in modulating the growth factors IGF-1 and Her-2/neu.

\section{PATIENTS and METHODS}

The study included 60 postmenopausal women with proven pathological diagnosis of breast cancer who were planned to receive tamoxifen-based regimen. The patients were recruited from Damietta Cancer Institute, Damietta, Egypt, under supervision of Dr. Hossam Darwish, from July 2010 to April 2011. Patients with history of heart failure, arrhythmia, under heart therapy, or impaired liver functions were excluded. Also, patients having concomitant complementary treatment or previous malignancies other than breast carcinoma were excluded.

The study participants were classified into two groups; 1) Control breast cancer group, which included newly diagnosed 20 breast cancer patients prior to surgery or receiving any treatment. 2) Tamoxifen group, which included 40 breast cancer patients who were treated with tamoxifen $20 \mathrm{mg} / \mathrm{day}$ (Amriya Pharm. Ind. Company, Egypt) for one to five years. Blood samples were collected from both groups at the start of study, then, TAM-treated patients were supplemented with oral L-carnitine 1g/day (Mepaco Company, Egypt) as adjuvant therapy for 6 months, after which second blood samples were collected. The patients of TAM group were followed closely to ensure that they stacked to the treatment.

Detailed history of patients was recorded. Menopausal status was categorized as 'postmenopausal', defined as the last menstrual period occurring more than 12 months prior to the date of recruitment into the study. The weight and height of patients were measured and body mass index (BMI) was calculated [weight $(\mathrm{kg}) /$ height $\left.\mathrm{t}^{2}\left(\mathrm{~m}^{2}\right)\right]$. The characteristics of the study participants are illustrated in Table (1).

The mean age of control breast cancer group was 52 years and that of TAM group was 54.3 years. The majority of women enrolled in the study were had their first age of menarche at age of 12-13 years, had married, had BMI $30 \mathrm{~kg} / \mathrm{m}^{2}$ or greater, had taken contraceptive pills, with number of pregnancies more than or equal to 4 , with a mean age of first and last birth of 19.9, 30.3 years, respectively. $32.5 \%$ of TAM group patients were with a family history of breast cancer and $25 \%$ with a family history of other types of cancer, whereas $35 \%$ of control breast cancer group were with a family history of breast cancer and $45 \%$ with a family history of other types of cancer. $72.5 \%$ of TAM group undergone ductal invasion and $87.5 \%$ mastectomy surgery, and had tumors that were estrogen receptor-positive. $47.5 \%$ of the TAM group patients were treated with TAM for 1-2 years (Table 1).

Five $\mathrm{mL}$ blood was drawn by venous arm puncture from patients after overnight fast. Blood was left to stand at room temperature in plain tube to allow clot formation and then serum was separated by centrifugation at $4000 \mathrm{rpm}$ for 15 min using 5804 centrifuge (Eppendorf International Company, German). Serum was divided into aliquots; tumor markers and hormonal marker were analyzed immediately and other aliquots were stored frozen at $-70{ }^{\circ} \mathrm{C}$ till analysis of Her-2/neu and IGF-1.

\subsection{Measurement of growth factors:}

Quantitative measurement of serum Her-2/neu and IGF-1 was carried out by enzyme-linked immunosorbent assay (ELISA) using kits obtained from RayBio ${ }^{\circledR}$ Human Her-2/neu (epidermal growth factor receptor-2) and RayBio ${ }^{\circledR}$ Human IGF-1 (insulin growth factor-1), respectively. The intensity of the color was measured at $450 \mathrm{~nm}$ using microplate reader (TECAN Austria GmbH 5082 Grodig, Austria).

1.2. Measurement of tumor and hormonal markers:

Microparticle enzyme immunoassay (MEIA) was utilized for quantitative determination of serum levels of carcinoembryonic antigen (CEA) [8], cancer antigen 15.3 (CA15.3) [9] and estradiol (E2) [10] using kits obtained from AxSym Chemical Co., USA and Abbott AxSym immunology analyzer.

\subsection{Statistical analysis:}

Data are presented as mean \pm standard error (SE) and were analyzed by Microsoft software (EXCEL 2000) and statistical package for social science (SPSS) version 17. Patients database were collected through Microsoft Office Access 2003. Pearson's correlation test was used for detection of the parametric correlation. The experimental data were analyzed for significant differences by independent Student's t-test based on differences between groups, and paired t-test based on differences before and after treatment within the same group. The level of significance was set at $\mathrm{P}<0.05$

\section{Results}

Table (2) shows Her-2/neu and IGF-1 in control breast cancer patients and TAM group before and after supplementation with L-carnitine for 6 months. TAM-treated patients showed significant decrease $(\mathrm{P}<0.05)$ in serum Her-2/neu and IGF-1 levels compared to control patients. Administration of L-carnitine to TAM group produced a significant decrease in serum Her-2/neu level $(\mathrm{P}<0.05)$ compared to each of control patients $(\%$ decrease 59.5\%) and TAM patients-before L-CAR (\% decrease 39.1\%). The lowering effect of TAM on IGF-1 $(\mathrm{P}<0.05,5.4 \% \downarrow)$ was maintained after L-CAR supplementation (Table 2). 
Table (3) presents the serum levels of CEA, CA15.3 (tumor markers) and E2 (hormonal marker) in the study patients. Although TAM exhibited no significant effect on estradiol level, it produced a significant decrease in both tumor markers CEA and CA15.3 ( $\mathrm{P}<0.05$, \% decrease $80.9 \%$ and $67.8 \%$, respectively). The lowering effect of TAM on tumor markers was maintained after supplementation of L-CAR for 6 months.

Correlation study revealed a significant positive correlation $(\mathrm{P}<0.05)$ between IGF-1 and each of Her2/neu (Fig. 1), E2 (Fig. 2), and BMI (Fig. 3). A significant positive correlation $(\mathrm{P}<0.05)$ was also obtained between E2 and BMI (Fig. 4).

Table (1): Characteristics of the studied breast cancer patients

\begin{tabular}{|c|c|c|c|c|}
\hline \multirow{2}{*}{ Patients' characteristics } & \multicolumn{2}{|c|}{ Control group $^{@}$} & \multicolumn{2}{|c|}{ TAM group } \\
\hline & No. & $\%$ & No. & $\%$ \\
\hline \multicolumn{5}{|l|}{ Age (years) } \\
\hline$<50$ & 7 & $35 \%$ & 14 & $35 \%$ \\
\hline$\geq 50$ & 13 & $65 \%$ & 26 & $65 \%$ \\
\hline \multicolumn{5}{|l|}{ "Body mass index (BMI) $\left(\mathrm{kg} / \mathrm{m}^{2}\right)$} \\
\hline $18.5-29.9$ & 10 & $50 \%$ & 11 & $27.5 \%$ \\
\hline$\geq 30.0$ & 10 & $50 \%$ & 29 & $72.5 \%$ \\
\hline \multicolumn{5}{|l|}{ Age at first menarche (years) } \\
\hline$\leq 12$ & 5 & $25 \%$ & 5 & $12.5 \%$ \\
\hline$>12$ & 15 & $75 \%$ & 35 & $87.5 \%$ \\
\hline \multicolumn{5}{|l|}{ Marital status } \\
\hline Married & 20 & $100 \%$ & 39 & $97.5 \%$ \\
\hline Not Married & 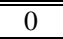 & $0 \%$ & 1 & $2.5 \%$ \\
\hline \multicolumn{5}{|l|}{ Hormonal therapy } \\
\hline Contraceptive bills & 15 & $75 \%$ & 26 & $65 \%$ \\
\hline Insulin & 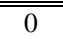 & $0 \%$ & 3 & $7.5 \%$ \\
\hline Thyroid hormones & 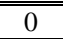 & $0 \%$ & 3 & $7.5 \%$ \\
\hline \multicolumn{5}{|l|}{ Number of pregnancies } \\
\hline $\begin{array}{ll} & 0 \\
\end{array}$ & 0 & $0 \%$ & 2 & $5 \%$ \\
\hline$\geq 4$ & 11 & $55 \%$ & 27 & $67.5 \%$ \\
\hline $2<4$ & 9 & $45 \%$ & 11 & $27.5 \%$ \\
\hline \multicolumn{5}{|l|}{ Number of abortions } \\
\hline $\begin{array}{c} \\
\end{array}$ & 99 & $45 \%$ & 24 & $60 \%$ \\
\hline$\geq 1$ & 11 & $55 \%$ & 16 & $40 \%$ \\
\hline \multicolumn{5}{|l|}{ Age at first birth (years) } \\
\hline$<20$ & $\overline{5} 5$ & $25 \%$ & 17 & $42.5 \%$ \\
\hline $\begin{array}{c}\geq 20 \\
\end{array}$ & 15 & $75 \%$ & 21 & $52.5 \%$ \\
\hline \multicolumn{5}{|l|}{ Age at last birth (years) } \\
\hline$\leq 30$ & 19 & $95 \%$ & 34 & $85 \%$ \\
\hline$>30$ & 1 & $5 \%$ & 4 & $10 \%$ \\
\hline \multicolumn{5}{|l|}{ Infertility } \\
\hline & 0 & $0 \%$ & 2 & $5 \%$ \\
\hline \multicolumn{5}{|l|}{ Age at menopause (years) } \\
\hline$\leq 50$ & 18 & $90 \%$ & 37 & $95 \%$ \\
\hline$>50$ & 2 & $10 \%$ & 3 & $7.5 \%$ \\
\hline \multicolumn{5}{|l|}{ Family history } \\
\hline \multicolumn{5}{|l|}{ Family history of breast cancer } \\
\hline $\begin{array}{l}\text { Family history of other type of } \\
\text { cancer }\end{array}$ & 9 & $45 \%$ & 10 & $25 \%$ \\
\hline No family history of cancer & 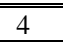 & $20 \%$ & 17 & $42.5 \%$ \\
\hline \multicolumn{5}{|l|}{ Start using tamoxifen (years ago) } \\
\hline $1-2$ & 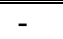 & 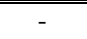 & 19 & $47.5 \%$ \\
\hline$>2-3$ & - & 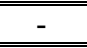 & 10 & $25 \%$ \\
\hline$>3-4$ & - & - & 8 & $20 \%$ \\
\hline$>4-5$ & 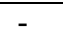 & - & 3 & $7.5 \%$ \\
\hline
\end{tabular}

@: : Total number of control group $=20$ patients

$\square$ :Total number of tamoxifen (TAM) group $=40$ patients 
Table (2): Serum levels of human epidermal receptor-2 (Her-2/neu) and insulin growth factor -1 (IGF-1) in the studied breast cancer patients

\begin{tabular}{|c||c|c|c|c|}
\hline Growth factor & $\begin{array}{c}\text { Control breast } \\
\text { cancer } \\
(\mathbf{n = 2 0})\end{array}$ & \multicolumn{3}{|c|}{$\begin{array}{c}\text { TAM group } \\
(\mathbf{n}=\mathbf{4 0})\end{array}$} \\
\hline \hline & Before L-CAR & After L-CAR & $\%$ Decrease \\
\hline \hline $\begin{array}{c}\text { Her-2/neu } \\
(\mathbf{p g} / \mathbf{m L})\end{array}$ & $407.6 \pm 3.9$ & $270.7 \pm 2.1^{\mathrm{a}}$ & $164.9 \pm 0.5^{\mathrm{a}, \mathbf{b}}$ & $39.1 \%$ \\
\hline \hline $\begin{array}{c}\mathbf{I G F - 1} \\
(\mathbf{n g} / \mathbf{m L})\end{array}$ & $0.386 \pm 0.009$ & $0.365 \pm 0.003^{\mathbf{a}}$ & $0.362 \pm 0.002^{\mathbf{a}}$ & $0.8 \%$ \\
\hline
\end{tabular}

Data are presented as mean $\pm \mathrm{SE}$

TAM: Tamoxifen, L-CAR: L-Carnitine

a: Significant versus control breast cancer at $\mathrm{P}<0.05$.

b: Significant versus TAM-before L-CAR at $\mathrm{P}<0.05$.

Table (3): Serum levels of tumor and hormonal markers in the studied breast cancer patients

\begin{tabular}{|c||c|c||c||}
\hline \multicolumn{1}{|c|}{$\begin{array}{c}\text { Tumor/Hormonal } \\
\text { marker }\end{array}$} & $\begin{array}{c}\text { Control breast } \\
\text { cancer } \\
(\mathbf{n = 2 0})\end{array}$ & \multicolumn{2}{|c|}{$\begin{array}{c}\text { TAM group } \\
(\mathbf{n}=\mathbf{4 0})\end{array}$} \\
\cline { 3 - 4 } & & Before L-CAR & After L-CAR \\
\hline \hline $\begin{array}{c}\mathbf{C E A} \\
(\mathbf{U} / \mathbf{m L})\end{array}$ & $6.8 \pm 0.6$ & $1.3 \pm 0.1^{\mathrm{a}}$ & $1.15 \pm 0.1^{\mathrm{a}}$ \\
\hline $\begin{array}{c}\mathbf{C A 1 5 . 3} \\
(\mathbf{U} / \mathbf{m L})\end{array}$ & $41.0 \pm 1.96$ & $13.2 \pm 0.7^{\mathrm{a}}$ & $12.4 \pm 0.6^{\mathbf{a}}$ \\
\hline \hline $\begin{array}{c}\mathbf{E 2} \\
(\mathbf{U} / \mathbf{m L})\end{array}$ & $16.1 \pm 1.7$ & $18.1 \pm 0.9$ & $15.1 \pm 0.9$ \\
\hline
\end{tabular}

Data are presented as mean \pm SE

TAM: Tamoxifen, L-CAR: L-carnitine

CEA: Carcinoembryonic antigen, CA15.3: Cancer antigen 15.3, E2: Estradiol

a: Significant versus control breast cancer at $\mathrm{P}<0.05$.

Reference values according to the kits: CEA: 0-3 U/mL, CA15.3: 0-28 U/mL, E2: 5-55 U/mL

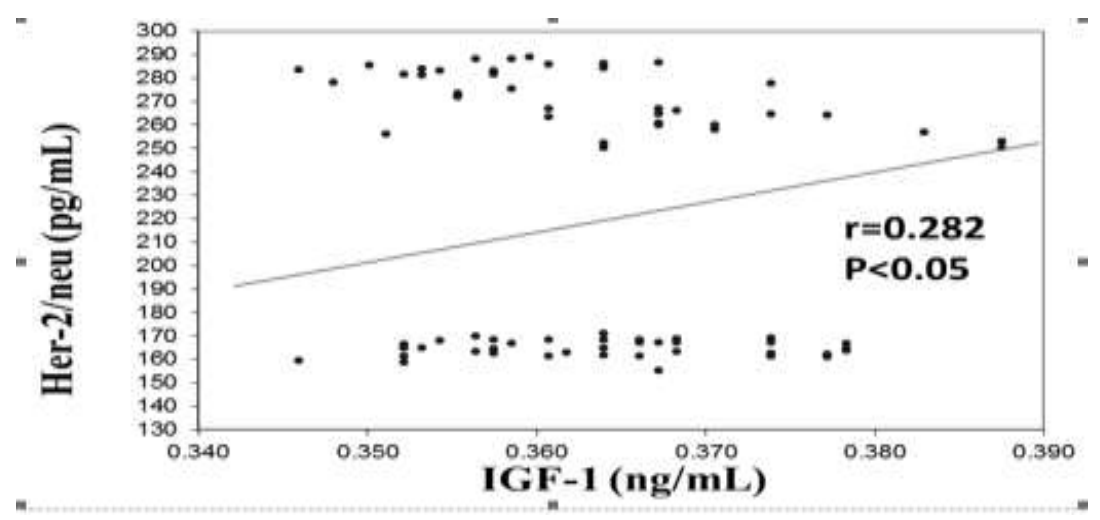

Figure (1): Correlation between serum insulin growth factor-1 (IGF-1) and human epidermal receptor-2

(Her-2/neu) in tamoxifen-treated breast cancer patients; $n=80$ 


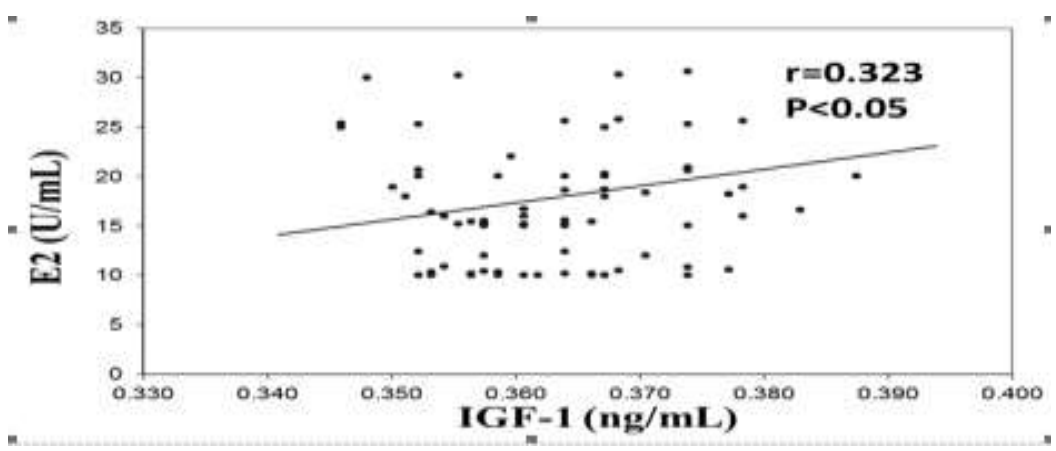

Figure (2): Correlation between serum insulin growth factor-1 (IGF-1) and estradiol (E2) in tamoxifentreated breast cancer patients; $\mathbf{n}=\mathbf{8 0}$

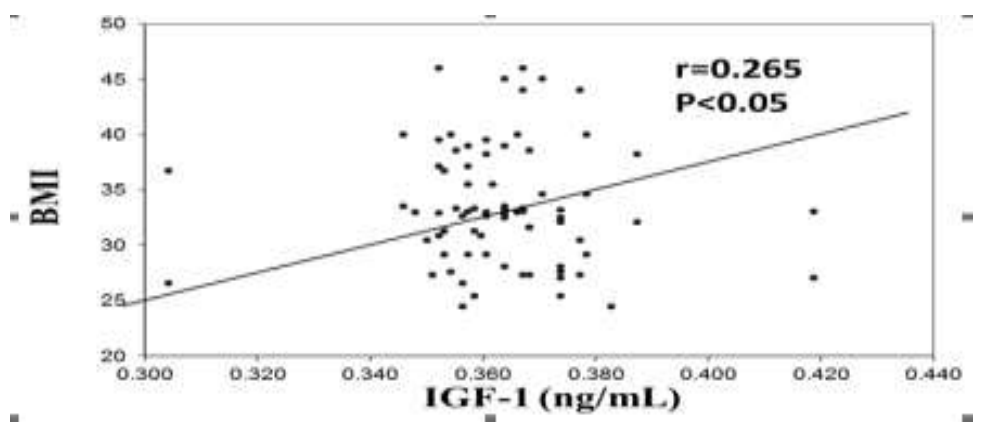

Figure (3): Correlation between serum insulin growth factor-1 (IGF-1) and body mass index (BMI) in tamoxifen-treated breast cancer patients; $\mathbf{n}=\mathbf{8 0}$

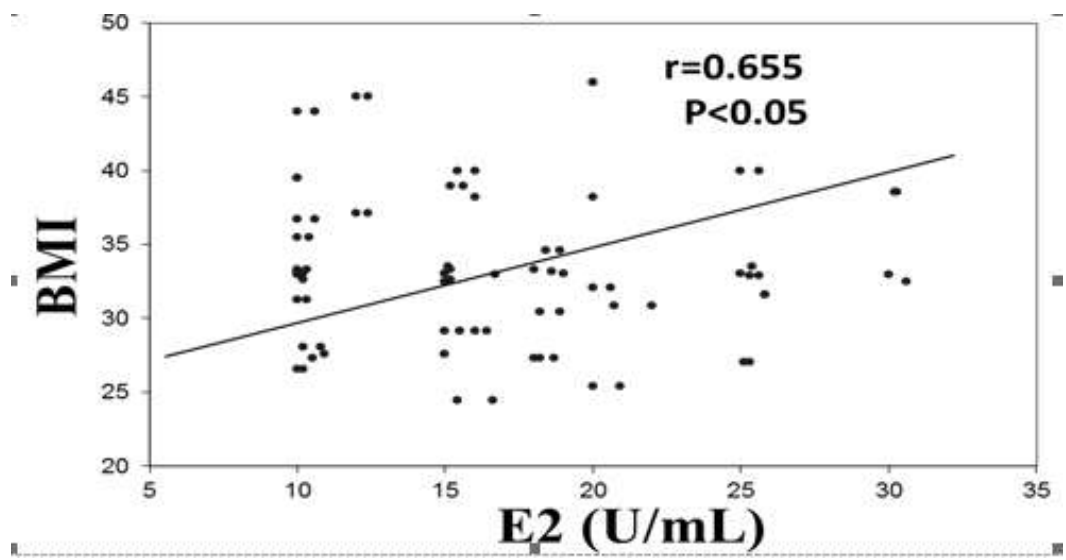

Figure (4): Correlation between serum estradiol (E2) and body mass index (BMI) in tamoxifen-treated breast cancer patients; $\mathbf{n = 8 0}$

\section{Discussion}

Sex hormones, especially estrogens, have been implicated in the development of breast cancer. Breast cancer risk increases after menopause, where aromatization of androgens to estrogens in adipose tissue is the most important source of estrogen in blood and peripheral tissues [11].

Weight increase and obesity subsequent to menopause have been identified as the most important risk and negative prognostic factors for breast cancer in postmenopausal women. Obesity results in increased circulating levels of insulin and insulin-like growth factor, which by acting as mitogens for epithelial breast cells, stimulate their growth and neoplastic degeneration. Mechanisms may combine to explain the association which links together menopause, the subsequent body weight increase, and hormone-dependent breast cancer [12].

Body mass index of tamoxifen-treated breast cancer patients included in the present study was positively correlated with estrogen level (E2) which is consistent with Mahabir et al. [11], who showed that the increased breast cancer risk seen in postmenopausal women with adiposity might be related to elevated sex hormone level. 
The present results showed that administration of TAM for 1-5 years to breast cancer patients decreased tumor markers CEA and CA15.3 significantly. Serum levels of CEA and CA15.3 represent the response of the disease to treatment and indicate the tumor suppressive effect of tamoxifen.

The antitumor activity of tamoxifen is attributed to its anti-estrogenic activity, which may be mediated by competitive inhibition of estrogen binding to ER. In addition, TAM inhibits the expression of estrogen regulated genes including the growth factors genes IGF-1 and Her-2/neu [13]. While the traditional role of ER is central to $\mathrm{ER}+$ breast cancer, ER has also been implicated in non-genomic, plasma membrane-initiated signaling with IGF-1 and epidermal growth factor receptor (EGFR) which are tyrosine kinases implicated in human breast cancer. IGF-1 and Her-2/neu could be secreted by the tumor and stimulate growth by autocrine or paracrine mechanisms [14].

Dossus and Kaaks [15] demonstrated that an approximate two-fold increase in risk of breast cancer was observed especially among women who had high IGF-1 levels. In the present work, IGF-1 was significantly decreased by TAM, which supports the good outcome of treatment. The findings of this work were in accordance with Dearth et al. [16], who demonstrated that patients with postmenopausal breast cancer showed a decrease of serum IGF-1 levels when treated with tamoxifen.

Although estrogen is the initial driving force for adult female mammary development, it requires growth hormone (GH)-induced insulin growth factor-1 (IGF-1) in the mammary gland in order to act [17]. IGF-1 is produced in the liver in response to pituitary GH and is also an important product of GH action in the mammary fat pad. As with several other growth factors, estrogen enhances the action of IGF-1 through a stromal epithelial interaction [18]. Our observations were in line because positive correlations were found between IGF-1 and each of E2 and BMI in the studied tamoxifen-treated breast cancer patients.

Radhakrishnan et al. [19] reported that IGF-1 acts as a mitogen for breast cancer cells mediated by downregulation of tyrosine phosphorylation and phosphatidylinositol 3'- kinase signaling. Due to the mitogenic and antiapoptotic effects of IGF-1 it has been implicated in several types of cancer including breast [20], prostate [21], lung [22] and colon cancer [23].

The present results indicated a significant positive correlation between IGF-1 and Her-2/neu in breast cancer patients. Over-expression of Her-2/neu protein is found in $15 \%$ to $25 \%$ of newly diagnosed invasive breast cancer [24]. Enhanced cell signaling secondary to the over-expression of Her-2/neu protein will culminate in increased cell proliferation, cell motility, cell survival, angiogenesis, invasion and metastasis. Her-2/neu has been widely studied as a therapeutic target and as a predictive marker for cancer therapy using specific Her2/neu antagonists [25].

Despite tamoxifen benefit in patients with all stages of ER-positive breast cancer, the major obstacle to its use is treatment resistance. There is some evidence that Her-2/neu status is a predictor for response/resistance to tamoxifen. Both pre-clinical and clinical studies suggest that the mechanism of resistance involves cross-talk between ER and growth factor and/or stress kinase signaling pathways that promote phosphorylation of the ER and its co-activators. This in turn activates breast cancer cell growth and then the resistance to endocrine therapy is experienced [26].

In the present study, TAM treatment to the breast cancer patients revealed a significant decrease in Her2/neu in serum when compared to control patients. This finding is in agreement with James et al. [27], who revealed that serum Her-2/neu levels may serve to monitor hormonal therapy in Her-2/neu positive breast cancer patients and that circulating Her-2/neu levels may be a better indicator of resistance to tamoxifen. Prospective trials are ongoing with the aim being to discover ways to delay or overcome the development of resistance to tamoxifen such as simultaneous blockage of different signal transduction pathways driven by EGFR [28].

L-carnitine supplementation to cancer patients enhances fatty acid metabolism in mitochondria, restores normal mitochondrial function, and so, improves patients` fatigue and quality of life [29]. Carnitine may also mimic some of the biological activities of glucocorticoids, particularily immunomodulation, via suppressing TNF- $\alpha$ and IL-12 release from monocytes (5). L-carnitine as adjuvant therapy in cisplatin-treated cancer patients proved a beneficial effect in reducing the cisplatin-induced organ toxicity [30].

The present work revealed that L-carnitine supplement combined to tamoxifen therapy produced a significant decrease in Her-2/neu in serum when compared to control group and to TAM-group before L-CAR. Previous studies indicated that Her-2/neu level was decreased in breast cancer cells in presence of the natural product green tea catechin [31].

It is possible that, the extremely lipophilic nature of carnitine may be responsible for the decrease in EGF binding [32]. Carnitine may insert in the cell membrane and/or interact with one of the many cellular enzymes having lipid substrates or cofactors. In addition, carnitine may interact directly with the EGFR [33].

Experimental evidence is available showing that ROS may induce the ligand-independent phosphorylation of the EGFR activating Her-2/neu. Moreover, the expression of the receptor is induced in conditions of oxidative stress [34]. L-carnitine, via its free radical scavenging and antioxidant properties, may 
inhibit ROS-mediated EGFR phosphorylation. It has been found that palmitoyl-carnitine can inhibit the activity of heart and brain protein kinase $\mathrm{C}$ in a competitive manner and subsequent phosphorylation of the EGFR [35].

Although the tumor markers and IGF-1 showed no significant difference in TAM-treated patients before and after administration of L-CAR, there was a tendency to decline after L-CAR supplementation. Waylan et al. [36] reported no change in circulating IGF-1 levels in sows (pigs) with or without L-carnitine supplementation.

\section{Conclusion}

The prominent role of $\mathrm{L}$-carnitine in the present study belongs to the level of Her-2/neu, which was significantly reduced after L-carnitine supplementation. Thus, L-CAR as add on therapy to TAM, in addition to its ability to foster the immune system and improve the patients` fatigue and quality of life, may offer better cancer prognosis, which may be, in part, a prospective trial to overcome tamoxifen resistance.

\section{References}

[1] V.C. Jordan and B.W. O'Malley, Selective estrogen-receptor modulators and antihormonal resistance in breast cancer, J Clin Oncol, 25(36), 2007, 5815-5824.

[2] J.S. Samaddar, V.T. Gaddy, J. Duplantier, S.P. Thandavan, M. Shah, M.J. Smith, D. Browning, J. Rawson, S.B. Smith, J.T. Barrett and P.V. Schoenlein, A role for macroautophagy in protection against 4-hydroxytamoxifen-induced cell death and the development of antiestrogen resistance, Mol Cancer Ther, 7(9), 2008, 2977-2987.

[3] M.R. Baneshi, P. Warner, N. Anderson, J. Edwards, T.G. Cooke and J.M. Bartlett, Tamoxifen resistance in early breast cancer: statistical modelling of tissue markers to improve risk prediction, Br J Cancer, 102(10), 2010, 1503-1510.

[4] S.R. Johnston, Enhancing the efficacy of hormonal agents with selected targeted agents, Clin Breast Cancer, 1, 2009, S28-S36.

[5] N.S. Porter, L.A. Jason, A. Boulton, N. Bothne and B. Coleman, Alternative medical interventions used in the treatment and management of myalgic encephalomyelitis/chronic fatigue syndrome and fibromyalgia. J Altern Complement Med, 16(3), 2010, 235249.

[6] W.J. Kraemer, J.S. Volek and C. Dunn-Lewis, L-carnitine supplementation: influence upon physiological function, Curr Sports Med Rep, 7(4), 2008, 218-223.

[7] C. Schubert, S. Hong, L. Natarajan, P.J. Mills and J.E. Dimsdale, The association between fatigue and inflammatory marker levels in cancer patients: a quantitative review, Brain Behav Immun, 21(4), 2007, 413-427.

[8] D.M. Thomson, J. Krupey, S.O. Freedman and P. Gold, The radioimmunoassay of circulating carcinoembryonic antigen of the human digestive system, Proc Natl Acad Sci USA, 64(1), 1969, 161-167.

[9] M. Gion, M. Plebani, R. Mione, C. Penzo, S. Meo and A. Burlina, Serum CA549 in primary breast cancer: comparison with CA15.3 and MCA, Br J Cancer, 69, 1994, 721-725.

[10] H. Passing and W. Bablok, A New Biometrical Procedure for Testing the Equality of Measurements from Two Different Analytical Methods, J Clin Chem, 21, 1983, 709-720.

[11] S. Mahabir, D.J. Baer, L.L. Johnson, T.J. Hartman, J.F. Dorgan, W.S. Campbell, B.A. Clevidence and P.R. Taylor, Usefulness of body mass index as a sufficient adiposity measurement for sex hormone concentration associations in postmenopausal women, Cancer Epidemiol Biomarkers Prev, 15(12), 2006, 2502-2507.

[12] A. Macciò and C. Madeddu, Obesity, inflammation, and postmenopausal breast cancer: therapeutic implications, Sci Wor J, 11, 2011, 2020- 2036

[13] F. Cappuzzo, L. Toschi, G. Tallini, G.L. Ceresoli, I. Domenichini, S. Bartolini, G. Finocchiaro, E. Magrini, G. Metro, A. Cancellieri, R. Trisolini, L. Crino, P.A,Jr, Bunn, A. Santoro, W.A. Franklin, M. Varella-Garcia and F.R. Hirsch, Insulin-like growth factor receptor 1 (IGFR-1) is significantly associated with longer survival in non-small-cell lung cancer patients treated with gefitinib, Ann Oncol, 17, 2006, 1120-1127.

[14] V.G. Premkumar, S. Yuvaraj, K. Vijayasarathy, S.G.D. Gangadaran and P. Sachdanandam, Effect of coenzyme Q10, riboflavin and niacin on serum CEA and CA15-3 levels in breast cancer patients undergoing tamoxifen therapy, Biol Pharm Bull, 30(2), 2007, 367370 .

[15] L. Dossus and R. Kaaks, Nutrition, metabolic factors and cancer risk, Best Prac \& Res Clin End \& Met, 22(4), 2008, 551-571.

[16] P.K. Dearth, I. Kuiatse, Y.F. Wang, L. Liao, S.G. Hilsenbeck, P.H. Brown, J. Xu and A.V. Lee, A moderate elevation of circulating levels of IGF-I does not alter ErbB2 induced mammary tumorigenesis, BMC Cancer, 11, 2011, 377-386.

[17] D.L. Kleinberg, T.L. Wood, P.A. Furth, A.V. Lee, Growth hormone and insulin-like growth factor-I in the transition from normal mammary development to preneoplastic mammary lesions, Endocr Rev, 30(1), 2009, 51-74.

[18] F.L. Queiroga, M.D. Pérez-Alenza, G. Silvan, L. Peña, C.S. Lopes and J.C. Illera, Crosstalk between GH/IGF-I axis and steroid hormones (progesterone, 17beta-estradiol) in canine mammary tumours, J Steroid Biochem Mol Biol, 110(1-2), 2008 , 76-82.

[19] Y. Radhakrishnan, W.H.Jr. Busby, X. Shen, L.A. Maile and D.R. Clemmons, Insulin-like growth factor-I-stimulated insulin receptor substrate-1 negatively regulates Src homology 2 domain-containing protein-tyrosine phosphatase substrate-1 function in vascular smooth muscle cells, J Biol Chem, 285(21), 2010, 15682-15695.

[20] Z. Davison, G.E. de Blacquiere, B.R. Westley and F.E. May, Insulin-like growth factor-dependent proliferation and survival of triple-negative breast cancer cells: implications for therapy, Neoplasia, 13, 2011, 504-515.

[21] M.L. Neuhouser, J. Schenk, Y.J. Song, C.M. Tangen, P.J. Goodman, M. Pollak, D.F. Penson, I.M. Thompson and A.R. Kristal, Insulin-like growth factor-I, insulin-like growth factor binding protein-3 and risk of benign prostate hyperplasia in the prostate cancer prevention trial, Prostate, 68(13), 2008, 1477-1486.

[22] M.J. Fidler, D.D. Shersher, J.A. Borgia and P. Bonomi, Targeting the insulin-like growth factor receptor pathway in lung cancer: problems and pitfalls, Ther Adv Med Oncol, 4(2), 2012, 51-60.

[23] Y.W. Moon, S. Park, J.H. Sohn, D.R. Kang, J.S. Koo, H.S. Park, H.C. Chung and B.W. Park, Clinical significance of progesterone receptor and HER2 status in estrogen receptor-positive, operable breast cancer with adjuvant tamoxifen, J Cancer Res Clin Oncol, 137(7), 2011, 1123-1130.

[24] R. Nahta, D. Yu, M.C. Hung, G.N. Hortobagyi and F.J. Esteva, Mechanisms of disease: understanding resistance to HER2-targeted therapy in human breast cancer, Nat Clin Pract Oncol, 3, 2006, 269-280.

[25] B.C. Browne, N. O'Brien, M.J. Duffy, J. Crown and N. O'Donovan, HER-2 signalling and inhibition in breast cancer, Curr Cancer Drug Ther, 9, 2009, 419-438.

[26] J.W. Uhr and K. Pantel, Controversies in clinical cancer dormancy, Proc Natl Acad Sci USA, 108(30), 2011, 12396-12400. 
[27] R. James, K. Thriveni, L. Krishnamoorthy, V. Deshmane, P.P. Bapsy and G. Ramaswamy, Clinical outcome of adjuvant endocrine treatment according to Her-2/neu status in breast cancer, Indian J Med Res, 133, 2011, 70-75.

[28] R.Y. Tsang and R.S. Finn, Beyond trastuzumab: novel therapeutic strategies in HER2-positive metastatic breast cancer, $B J$ Cancer, 106, 2012, 6-13.

[29] G. Sener, E. Ekşioğlu-Demiralp, M. Cetiner, F. Ercan, S. Sirvanci, N. Gedik and B.C. Yeğen, L-Carnitine ameliorates methotrexateinduced oxidative organ injury and inhibits leukocyte death, Cell Biol Toxicol, 22(1), 2006, 47-60.

[30] A. Arcangeli, O. Crociani, E. Lastraioli, A. Masi, S. Pillozzi and A. Becchetti, Targeting ion channels in cancer: a novel frontier in antineoplastic therapy, Curr Med Chem, 16(1), 2009, 66-93.

[31] T. Puig, J. Relat, P.F. Marrero, D. Haro, J. Brunet and R. Colomer, Green tea catechin inhibits fatty acid synthase without stimulating carnitine palmitoyltransferase-1 or inducing weight loss in experimental animals, Anticancer Res, 28(6A), 2008, 36713676.

[32] J. Doberenz, C. Birkenfeld, H. Kluge and K. Eder, Effects of L-carnitine supplementation in pregnant sows on plasma concentrations of insulin-like growth factors, various hormones and metabolites and chorion characteristics, J Anim Physiol Anim Nutr (Berl), 90(11-12), 2006, 487-499.

[33] S. Husain, C.E. Crosson, Role of PKCepsilon in PGF2alpha-stimulated MMP-2 secretion from human ciliary muscle cells, $J$ Ocul Pharmacol Ther, 24(3), 2008, 268-77.

[34] H.L. Chan, H.C. Chou, M. Duran, J. Gruenewald, M.D. Waterfield, A. Ridley and J.F. Timms, Major role of epidermal growth factor receptor and Src kinases in promoting oxidative stress-dependent loss of adhesion and apoptosis in epithelial cells, J Biol Chem, 285(7), 2010, 4307-4318.

[35] C.I. Campbell, J.J. Petrik and R.A. Moorehead, ErbB2 enhances mammary tumorigenesis, oncogene-independent recurrence and metastasis in a model of IGF-IR-mediated mammary tumorigenesis, Mol Cancer, 9, 2010, 235-250.

[36] A.T. Waylan, J.P. Kayser, D.P. Gnad, J.J. Higgins, J.D. Starkey, E.K. Sissom, J.C. Woodworth and B.J. Johnson, Effects of Lcarnitine on fetal growth and the IGF system in pigs, J Anim Sci, 83(8), 2005, 1824-1831. 